\title{
Protective effects of intracerebroventricular adiponectin against olfactory impairments in an amyloid $\beta_{1-42}$ rat model
}

\author{
Mara A. Guzmán-Ruiz ' , Amor Herrera-González , Adriana Jiménez , Alan Candelas-Juárez', \\ Crystal Quiroga-Lozano', Claudia Castillo-Díaz , Erika Orta-Salazar², Diana Organista-Juárez', \\ Sofía Díaz-Cintra ${ }^{2}$ and Rosalinda Guevara-Guzmán ${ }^{*^{*}(\mathbb{B})}$
}

\begin{abstract}
Background: Alzheimer's disease (AD) is characterized by cognitive impairment that eventually develops into dementia. Amyloid-beta $(A \beta)$ accumulation is a widely described hallmark in $A D$, and has been reported to cause olfactory dysfunction, a condition considered an early marker of the disease associated with injuries in the olfactory bulb (OB), the hippocampus (HIPP) and other odor-related cortexes. Adiponectin (APN) is an adipokine with neuroprotective effects. Studies have demonstrated that APN administration decreases A $\beta$ neurotoxicity and Tau hyperphosphorylation in the HIPP, reducing cognitive impairment. However, there are no studies regarding the neuroprotective effects of APN in the olfactory dysfunction observed in the A $\beta$ rat model. The aim of the present study is to determine whether the intracerebroventricular (i.c.v) administration of APN prevents the early olfactory dysfunction in an i.c.v Amyloid-beta ${ }_{1-42}\left(A \beta_{1-42}\right)$ rat model. Hence, we evaluated olfactory function by using a battery of olfactory tests aimed to assess olfactory memory, discrimination and detection in the A $\beta$ rat model treated with APN. In addition, we determined the number of cells expressing the neuronal nuclei (NeuN), as well as the number of microglial cells by using the ionized calcium-binding adapter molecule 1 (Iba-1) marker in the OB and, CA1, CA3, hilus and dentate gyrus (DG) in the HIPP. Finally, we determined Arginase-1 expression in both nuclei through Western blot.

Results: We observed that the i.c.v injection of $A \beta$ decreased olfactory function, which was prevented by the i.c.V administration of APN. In accordance with the olfactory impairment observed in i.c.v A $\beta$-treated rats, we observed a decrease in NeuN expressing cells in the glomerular layer of the OB, which was also prevented with the i.c.v APN. Furthermore, we observed an increase of Iba-1 cells in CA1, and DG in the HIPP of the A $\beta$ rats, which was prevented by the APN treatment.
\end{abstract}

Conclusion: The present study describes the olfactory impairment of $A \beta$ treated rats and evidences the protective role that APN plays in the brain, by preventing the olfactory impairment induced by $A \beta_{1-42}$. These results may lead to APN-based pharmacological therapies aimed to ameliorate AD neurotoxic effects.

Keywords: Adiponectin, Amyloid-beta, Alzheimer disease model, Hippocampus, Olfactory bulb, Olfactory dysfunction

*Correspondence: rguevara@unam.mx

1 Departamento de Fisiología, Facultad de Medicina, Universidad Nacional Autónoma de México (UNAM), Mexico City, Mexico

Full list of author information is available at the end of the article

\section{Background}

Alzheimer disease (AD) is a neurodegenerative condition, characterized by the accumulation of insoluble forms of amyloid-beta $(\mathrm{A} \beta)$ and intracellular aggregation 
of the phosphorylated microtubule-associated protein tau (p-TAU) $[1,2]$. This results in neurodegeneration and cognitive impairment, including memory and olfactory dysfunction [3-6].

Olfactory impairment is considered an early marker for AD since odor sensibility, detection, and discrimination are significantly reduced in up to $70-95 \%$ of these patients [4-7]. Postmortem studies in humans and rodent models of $A D$ show a direct correlation between the amount of soluble oligomeric forms of $A \beta$ and the severity of olfactory impairments [7-10]. Accumulation of $A \beta$ oligomers $(A \beta O)$ in olfactory regions such as the olfactory epithelium, olfactory bulb (OB), anterior olfactory nucleus, piriform cortex, entorhinal cortex and hippocampus (HIPP) correlate with deficits in odor discrimination [6].

Conversely, disorders such as obesity, metabolic syndrome and type 2 diabetes are risk factors for the development of neurodegenerative pathologies such as $\mathrm{AD}$ $[11,12]$.

Adiponectin is an adipokine mainly secreted by mature white adipocytes, although it is also found in skeletal muscle, cardiac myocytes, and endothelial cells, and its secretion levels are inversely correlated with adiposity and insulin resistance [13].

There are several APN isoforms: (1) a full-length protein present in plasma that exists as a trimer, known as the low molecular weight isoform (LMW), (2) an hexamer, known as the middle molecular weight form (MMW) and (3) a 12- to 18-mer, constituting the high molecular weight (HMW) form. APN can also be found in a globular form, constituted by the C-terminal domain as a result from proteolytic cleavage. The LMW, the MMW and the globular forms of APN have been found in the central nervous system (CNS) [14-16].

APN is known for its pleiotropic actions, regulating a wide range of physiological processes such as: glucose and fatty acid metabolism, insulin sensitivity (in peripheral tissues and brain), the immune response and oxidative stress $[13,17,18]$.

The effects of APN are carried out through the activation of adiponectin receptors 1 and 2 (AdipoR 1 and 2) [19-21] and the T-cadherin receptor, which is mainly expressed in the intima of the vascular endothelium [22, 23].

In the CNS, APN has an important neuroprotective role because it restores neuronal insulin signaling via the phosphorylation of the insulin receptor substrate-1 (IRS-1), enhancing cognitive performance in neurodegenerative models of $\mathrm{AD}[24,25]$. Furthermore, APN inhibits microglial pro-inflammatory responses to LPS and $\mathrm{A} \beta \mathrm{O}$, thus preventing cytotoxicity $[26,27]$. In acute inflammatory events like cerebral ischemia, it inhibits the infiltration of immune cells into the brain parenchyma [28].

APN knockout (APN-KO) mice exhibit AD-like memory impairments and anxiety, accompanied by the accumulation of oligomers $A \beta_{1-42}$ and p-TAU in the hippocampus [24]. A similar effect has been observed in the AdipoR1 knockdown (KD) [29], suggesting that impaired APN signaling in the brain might be involved in the pathogenesis of neurodegenerative diseases like AD.

In spite of the documented anti-inflammatory role of APN in the CNS, its role in the pathogenesis of neurodegenerative diseases is unclear. There is contrasting data regarding APN levels in different dementias, on one hand, APN is significantly higher in mild cognitive impairment and $\mathrm{AD}$ patients [30], on the other hand, the cerebrospinal fluid (CSF) levels of this adipokine are significantly low [31]. There is also conflicting data regarding increased CSF adiponectin in neurodegenerative diseases, which authors have suggested to be a counterregulatory effect to neurodegeneration [32]. Therefore, it is unclear whether this adipokine could exert a protective effect in neurodegenerative diseases such as AD.

In the present study, we hypothesized that the i.c.v. administration of APN would prevent the early olfactory dysfunction observed in a $A \beta_{1-42}$ rat model, which would correlate with a decrease in Iba- 1 expression in the HIPP and the prevention of the decrease of NeuN expressing cells in the glomerular layer in the $\mathrm{OB}$ in $\mathrm{A} \beta$ rats. For this, we first determined whether the intracerebroventricular (i.c.v.) administration of APN prevented the early olfactory dysfunction in an i.c.v. Amyloidbeta $_{1-42}\left(A \beta_{1-42}\right)$ rat model by using a battery of olfactory tests aimed to assess olfactory memory, discrimination and detection. In addition, we determined the number of cells expressing the neuronal nuclei (NeuN) marker, mainly located in the nuclei and perinuclear cytoplasm of mature neurons as an indication of neuronal differentiation. Next, we determined the number of microglial cells by using the ionized calcium-binding adapter molecule 1 (Iba-1) marker in the OB and HIPP We observed changes in this marker, suggesting a local inflammatory process in the brain. Finally, we determined the expression of the M2 microglial marker, Arginase 1 (ARG-1), observing an increase in the OB and the HIPP in response to APN i.c.v. administration.

\section{Results}

l.c.v. injection of adiponectin prevents olfactory memory impairment in the $A \beta_{1-42}$ rat model

To determine olfactory memory in our $A \beta$ rat model, we performed a social recognition test and habituation-dishabituation tests. 
In the social recognition test we measured the time that animals spent exploring a novel or a familiar juvenile rat and observed that VEH and APN treated rats spent significantly more time exploring a novel juvenile as compared to a familiar subject. In contrast, the $A \beta$ injected animals spent the same time exploring both novel and familiar juveniles. Interestingly, rats injected with APN$A \beta$, present similar exploration times as the VEH and APN groups (Fig. 1a-d).

To ensure that the differences in the time spent sniffing the familiar and unfamiliar juveniles were not due to motility impairments, we measured the exploring time of the void cages during the habituation trial, observing that the exploration time of all groups was similar (Fig. 1e).

To further evaluate olfactory memory, we employed the habituation-dishabituation test, which measures the time the animals spend smelling a scented histological cartridge in three consecutive trials for three different odors.

We observed that the $A \beta$ group was unable to dishabituate in response to new odors as compared to the $\mathrm{VEH}$ and $\mathrm{APN}$ rats. In contrast, the animals administered with APN-A $\beta$ only dishabituated with the coconut scent (Fig. 1f-i).

To determine if the differences in this test were not due to motility impairments, we compared the total amount of time that the animals sniffed each of the histological cartridges in all of the trials including water, observing no statistical differences (Fig. 1j). This demonstrates that all groups had the same motility and interest to explore the different cartridges. In addition, we observed that the habituation-dishabituation curves of intact and VEH were no different (Additional file 1: Fig. S1) demonstrating that the surgery did not interfere with the performance during this test.

\section{I.c.v. injection of adiponectin prevents odor discrimination} impairment in an $A \beta_{1-42}$ rat model

To evaluate odor discrimination, we performed the block test [23], which evaluates the capacity to recognize their own scent (blocks A-B) from the odor of another subject (block D).

We observed that the VEH and APN-treated groups explored block (D) significantly more as compared to their own $(A-B)$. In contrast, the $A \beta$ group spent the same time exploring all the blocks, while the APN-A $\beta$ group investigated block D significantly more (Fig. 1k$\mathrm{n})$. These results suggest that APN prevents the odor discrimination impairments in the $A \beta$-treated rats. Importantly, total exploration time of the three blocks presented no significant differences amongst the groups, suggesting that the differences in block exploration were not attributed to motility impairments (Fig. 1o).

\section{Olfactory bulb immunohistochemical evaluation of NeuN and Iba-1}

To determine whether APN prevents NeuN and Iba-1 changes in primary regions involved in processing odors, we evaluated NeuN and Iba-1 expression in two different regions of the OB (Fig. 2a).

First, we evaluated the granular cell layer (GCL) and observed no changes in the number of cells expressing neither NeuN nor Iba-1 (Fig. 2b-d).

Next, we evaluated the number of NeuN expressing cells in the glomerular layer (GL) of the OB and detected an increase in the APN group, as well as a decrease in the $\mathrm{A} \beta$ treated rats. The decrease in NeuN-IR cells in the $A \beta$ groups was prevented by APN (Fig. 2e, f). We did not observe changes in the amount of Iba-1 expressing cells in this region (Fig. 2g).

Finally, none of the areas beneath the glomerular layer including the external plexiform, the mitral/tufted cell area, the inner plexiform layer (data not shown), and the GL presented changes neither in the number of NeuN expressing cells nor in the thickness of the layers.

\section{Olfactory bulb Western blot evaluation of $A \beta$ oligomers and Arginase-1}

Since we observed a decrease in NeuN expression in the GL, we assessed if this effect could be related to the presence of $A \beta O$. We observed no differences in the amount of $A \beta O$ in the $O B$ of $A \beta$ or $A P N-A \beta$ treated rats (Fig. 3a and b, Additional file 3: Fig. S3B, D).

Next, since APN is known for its anti-inflammatory effects [24], we evaluated Arginase-1 (ARG-1), a microglial marker mainly expressed when these cells polarize to a neuroprotective phenotype M2 [25]. We observed that rats injected only with APN significantly increased ARG-1 expression in the OB as compared to the VEH treated animals. In addition, the rats treated with APN-A $\beta$ only presented a tendency to increase ARG-1 expression of this marker without reaching statistical significance (Fig. 3c and d, Additional file 4: Fig. S4A, B).

\section{Hippocampal immunohistochemical evaluation of NeuN and Iba-1}

To determine if our APN treatment could prevent hippocampal damage caused by the administration of $A \beta$, we performed a histological evaluation of the HIPP, where we determined the number of cells expressing NeuN and Iba-1. We did not find changes in the number of hippocampal NeuN expressing cells in any of the treatments (Fig. 4a, c, e, g).

Furthermore, we observed that $A \beta$ administration induced a significant increase in Iba-1 positive cells in CA1, CA3 and dentate gyrus (DG). Only the CA1 and 

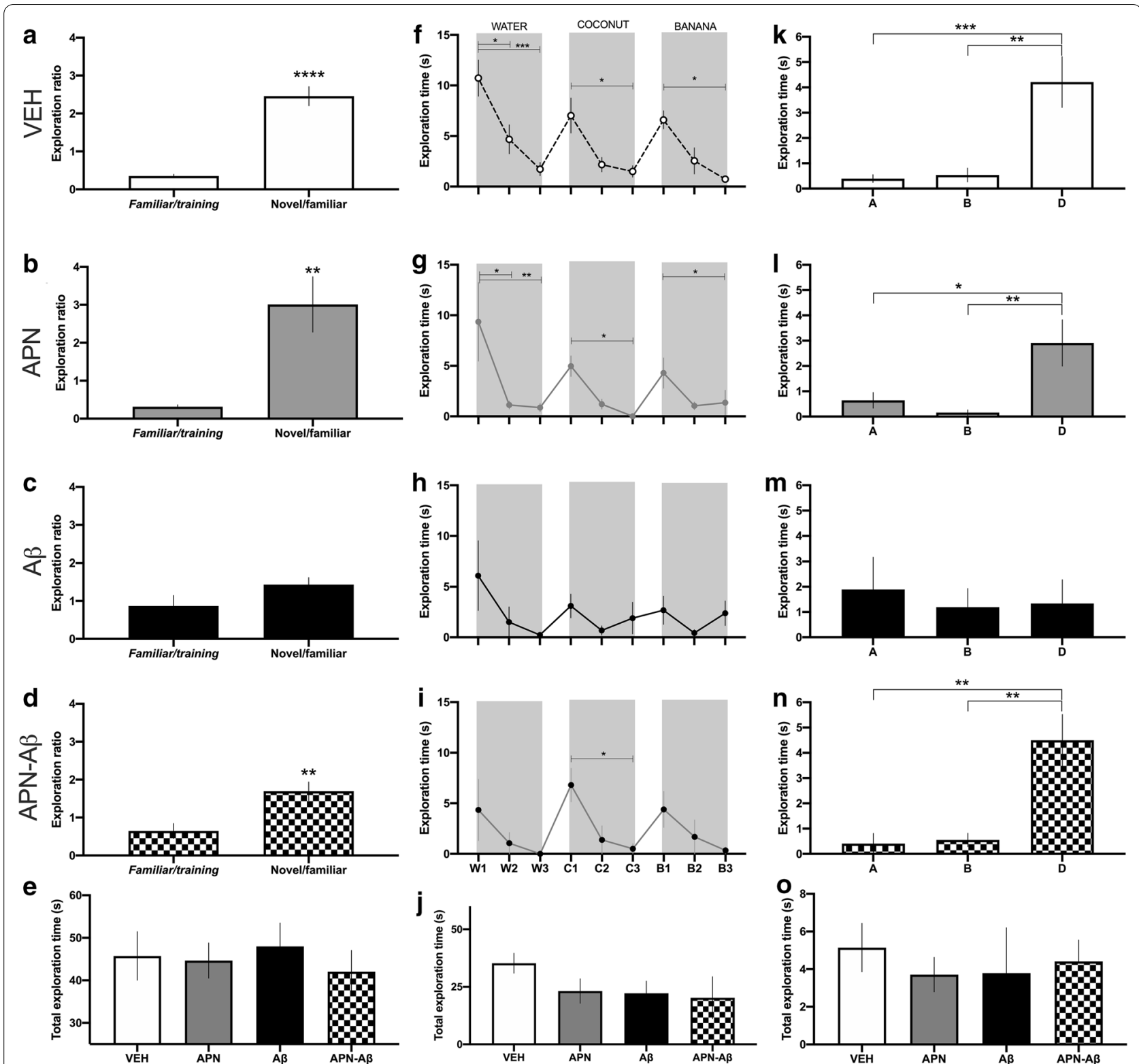

Fig. 1 Olfactory memory and discrimination tests. Social recognition test: a exploration time in the social recognition test of vehicle group (VEH), $\mathbf{b}$ adiponectin and vehicle group (APN), $\mathbf{c}$ vehicle and $A \beta(A \beta)$ and $\mathbf{d}$ adiponectin $A \beta_{1-42}$ (APN-A 3 ). The first bar denotes the exploration ratio between the juvenile 1 familiar/training and the second bar shows the exploration ratio between the novel/familiar, e total exploration time of both cages during the habituation trial $\left(F_{[8,63]}=8.277, p<0.0001\right)$. Habituation-dishabituation test: time smelling a cassette with different essences for f $\mathrm{VEH}\left(\mathrm{F}_{[8,63]}=8.277, \mathrm{p}<0.0001\right), \mathbf{g} \mathrm{APN}\left(\mathrm{F}_{[8,34]}=3.843, \mathrm{p}<0.0026\right), \mathbf{h} \mathrm{A} \beta\left(\mathrm{F}_{[8,54]}=1.354, \mathrm{p}<0.2377\right.$, and $\mathbf{i} \mathrm{APN}-\mathrm{A} \beta\left(\mathrm{F}_{[8,35]}=2.346, \mathrm{p}<0.0391\right), \mathrm{W} 1-3$ corresponds to the three trials where the cassette was loaded with $50 \mu \mathrm{l}$ of water; C1-3 with $50 \mu \mathrm{l}$ of coconut extract; and B1-3 $50 \mu \mathrm{l}$ of banana extract, $\mathbf{j}$ total exploration time for all of the essences and water $\left(\mathrm{F}_{[3,19]}=1.455, \mathrm{p}<0.2584\right)$. Block test: time exploring each block for the groups $\mathbf{k}$ $\operatorname{VEH}\left(F_{[2,18]}=12.66, p<0.0004\right)$, I APN $\left(F_{[2,15]}=6.866, p<0.0076\right), \mathbf{m} A \beta\left(F_{[2,15]}=0.1347, p<0.8750\right)$ and $\mathbf{n}$ APN $-A \beta\left(F_{[2,21]}=12.68, p<0.0002\right)$. First and second bars represent the time spent smelling two blocks that were placed in their own cage the night before. The third bar represents the time animals spent smelling a block from the cage of a different animal. o Total exploration time of the three blocks $\left(F_{[3,23]}=0.1752 p<0.9121\right)$. Data are presented as SEM and evaluated using a Student's T test (a-d) or a One-way ANOVA with a post-hoc Tukey test (e-o). Asterisks represent significance $\left({ }^{*} p<0.05,{ }^{* *} p<0.001\right)$ 


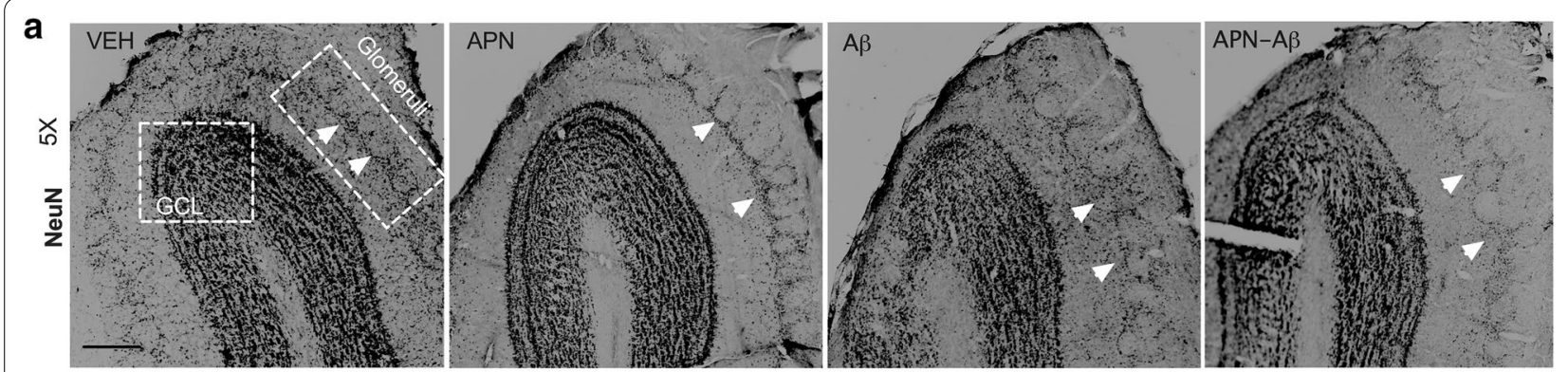

b
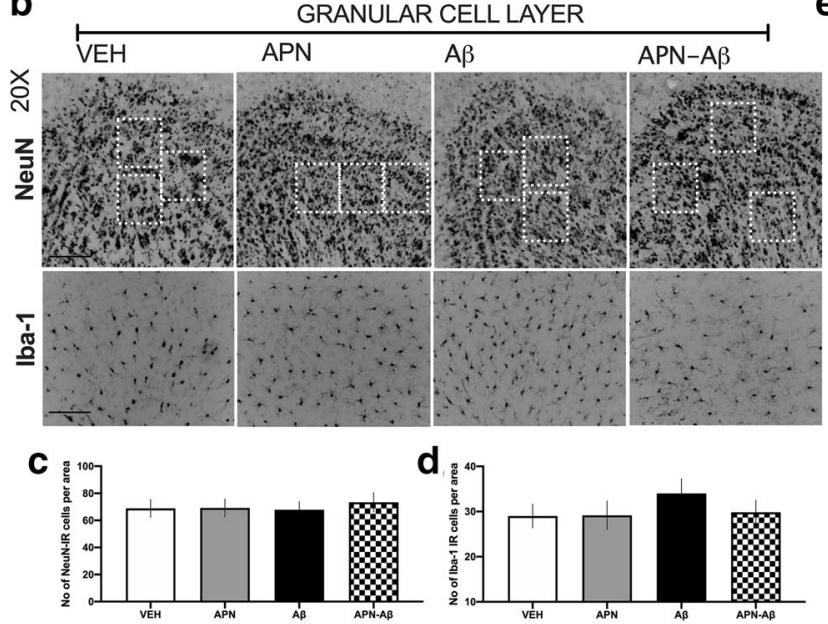

e
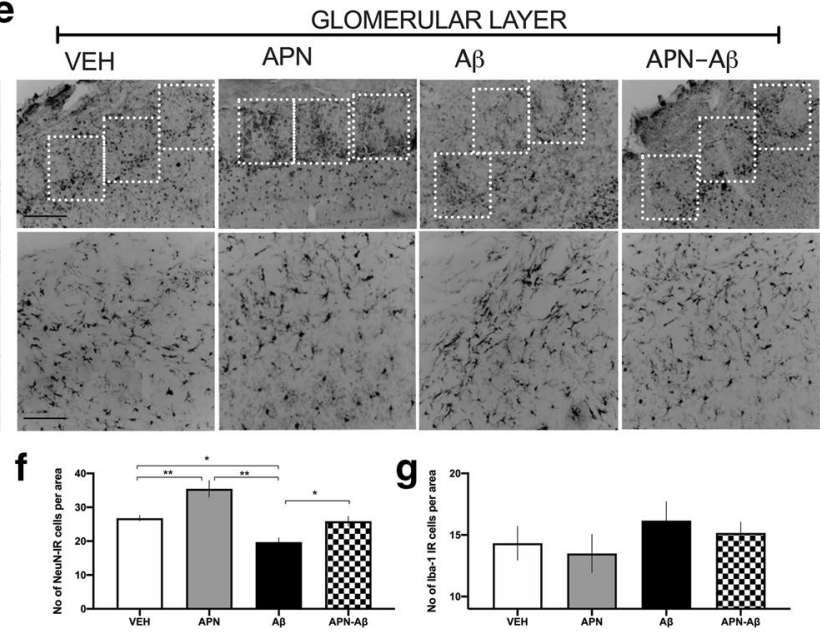

Fig. 2 Immunohistological determination of NeuN and Iba-1 expression in the olfactory bulb. a Representative micrographies of the olfactory bulb showing the evaluated areas for NeuN and Iba-1, scale bar $250 \mu \mathrm{m}$; the arrows denote the region where glomeruli are disarranged. b Representative micrographies of NeuN (top) and Iba-1 (bottom) of the granular cell layer (GCL) with examples of the random squares (ROls) quantified, scale bar $50 \mu \mathrm{m}$. $\mathbf{c}$ Number of NeuN expressing cells in the $\mathrm{GCL}$ for Vehicles $(V E H)$, adiponectin $(A P N)$, Amyloid- $\beta\left(A \beta\right.$ and $A P N-A \beta$ injected rats $\left(F_{[3,20]}=0.1\right.$, $p<0.94)$. $\mathbf{d}$ Number of Iba-1 positive cells per area of the $G C L$ of the same groups $\left(F_{[3,20]}=0.6336\right.$, $\left.p<0.602\right)$. e Representative micrographies of the glomeruli with examples of the random squares (ROls) quantified, scale bar $50 \mu \mathrm{m}$. $\mathbf{f}$ Number of NeuN expressing cells in the glomeruli per area of the same groups $\left(F_{[3,68]}=15.93, p<0.0001\right)$. $\mathbf{g}$ Circularity index of the glomeruli of the same groups $\left(F_{[3,312]}=79.54, p<0.0001\right)$. $\mathbf{h}$ Number of Iba-1 positive cells per area $\left(\mathrm{F}_{[3,20]}=0.7029, \mathrm{p}<0.5614\right.$. Data are presented as SEM and evaluated using a One-way ANOVA with a post-hoc Tukey test
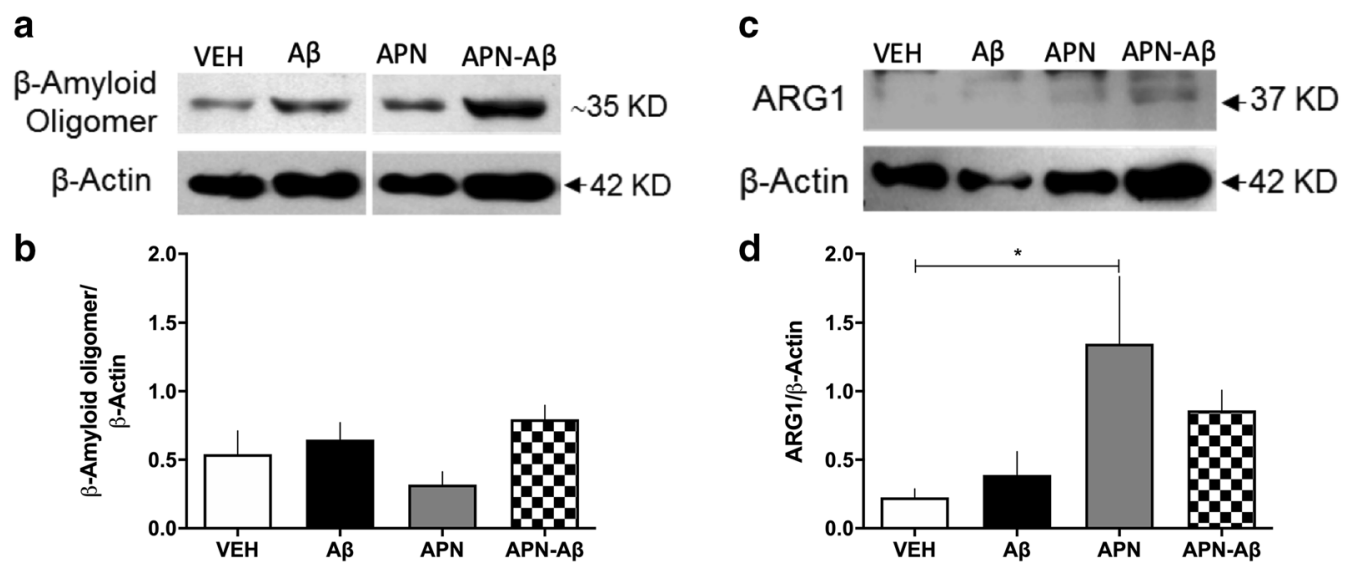

Fig. 3 Protein expression in the olfactory bulb. a Representative Western blot of Amyloid $\beta$ oligomer and $\beta$-Actin; $\mathbf{b} \beta$-Amyloid/ $\beta$-Actin ratio; $\mathbf{c}$ representative Western blot of Arginase1 (ARG1) and $\beta$-Actin; $\mathbf{d}$ ARG1/ $\beta$-Actin ratio for the vehicles (VEH), adiponectin (APN), Amyloid $\beta$ (AB) and APN-A injected rats. Data are presented as SEM and evaluated using a One-way ANOVA with a post-hoc Tukey test 


\section{(See figure on next page.)}

Fig. 4 Hippocampal NeuN and Iba-1 expressing cells per area. In the top there is a representative micrography $(\times 4)$ of the evaluated hippocampal regions (scale bar $200 \mu \mathrm{m}$ ) with the regions evaluated for NeuN and Iba-1. a CA1 NeuN $\left(F_{[3,20]}=0.2144, p=0.8852\right)$ and $\mathbf{b} \mathrm{lba}-1\left(F_{[3,20]}=5.4\right.$, $p=0.0069)$ positive cells per area. $\mathbf{c} C A 3 \operatorname{NeuN}\left(F_{[3,20]}=0.1392, p=0.9354\right)$ and $\mathbf{d} \mid \mathrm{bba}-1\left(F_{[3,20]}=4.08, p=0.02\right)$ expressing cells per area. e Hippocampal hilus NeuN $\left(F_{[3,20]}=0.2 .338, p=0.1042\right)$ and $\mathbf{f} \mid \mathrm{ba}-1\left(F_{[3,20]}=1.553, p=0.2319\right)$ expressing cells per area. $\mathbf{g}$ Dentated Gyrus (DG) $\operatorname{NeuN}\left(F_{[3,20]}=0.05, p=0.985\right)$ and $\mathbf{h} \mid \mathrm{ba}-1\left(F_{[3,20]}=5.785, p=0.0051\right)$ expressing cells per area for the vehicles $(\mathrm{VEH})$, adiponectin (APN), Amyloid- $\beta$ $(A B)$ and $A P N-A \beta$ injected rats. Data are presented as mean + SEM and evaluated using a One-way ANOVA with a post-hoc Tukey test. Asterisks represent significant differences $\left({ }^{*} p<0.05,{ }^{* *} p<0.01\right)$. Higher magnifications of each region for both antibody stainings are presented in Additional file 1: Fig. S1

GD regions showed a significant reduction in the number of Iba1-positive cells as a result of the APN treatment prior to $A \beta$ administration (Fig. $4 \mathrm{~b}, \mathrm{~d}, \mathrm{~h}$ and Additional file 2: Fig. S2).

\section{Hippocampal Western blot evaluation of $A \beta$ oligomers and Arginase-1}

Since we observed changes in Iba-1 expression in the HIPP, we evaluated if this could be related to the presence of $A \beta O$. We observed no increase in $A \beta O$ neither in the $A \beta$ nor in the APN-A $\beta$ treated animals (Fig. $5 \mathrm{a}$ and $b$, Additional file 3: Fig. S3A, C).

Finally, we evaluated the microglial marker ARG-1, and found a significant increase only in the APN group as compared to the VEH and $A \beta$ treated animals.

Similar to the OB ARG- 1 in the APN-A $\beta$ rats there was a tendency to increase its expression without reaching significance (Fig. 5c and d, Additional file 4: Fig. S4A, B).

\section{Discussion}

In the present work, we employed three behavioral tests to evaluate the olfactory performance of rats injected with $A \beta_{1-42}$. We observed that rats administered with $A \beta$ presented impairments in olfactory detection and memory, which were prevented with i.c.v. APN. These results are in agreement with previous studies reporting olfactory impairments in humans with different dementias and in rodent models of neurodegenerative diseases [6].

In the present study, we did not find significant changes in $\mathrm{A} \beta \mathrm{O}$ accumulation in OB or HIPP. This is contrast with what has been reported in genetic models such as the A $\beta P P / P S 1$ and $\mathrm{Tg} 2576$ where $\mathrm{A} \beta \mathrm{O}$ accumulation appears at 3 months of age $[6,8,10]$, or in chronic models, where $\mathrm{A} \beta \mathrm{O}$ is accumulated in high quantities [33-36]. The lack of accumulation is probably due to brain clearance mechanisms, given that the infusions were performed in previously healthy animals $[37,38]$. Although there are few reports showing the presence of $A \beta_{1-42} 2-7$ weeks after an acute i.c.v. administration, these measurements were performed by immunohistochemistry and not western blot like in the present study $[39,40]$. Therefore, it is possible that the lack of visualization of the aggregates in this acute protocol are due to the visualization technique, since the dose of $\mathrm{A} \beta \mathrm{O}$ was similar to ours.

We believe that, although the clearance rate is probably enough to prevent accumulation of $\mathrm{A} \beta \mathrm{O}$, it is unable to prevent $A \beta O$ 's acute effects in the local circuitries of the $\mathrm{OB}$ that induce olfactory impairments.

The interconnections in the $\mathrm{OB}$ are complex, the glomerular layer receives excitatory inputs from olfactory sensory neurons that mainly contact periglomerular (PCs) and superficial axon cells (sSC), these are interneurons that establish bidirectional contacts with other regions in the OB [41]. PCs inhibit mitral cells (MCs), and this last ones communicate back to glomeruli through excitatory connections, increasing the firing of the surrounding neurons [41]. Studies have demonstrated that the connectivity of the $\mathrm{OB}$ neural circuits as well as olfactory performance are disturbed in mice overexpressing human APPsw, even before the onset of plaque accumulation [42].

Furthermore, in ex vivo experiments, acute incubation of the $\mathrm{OB}$ with oligomeric $\mathrm{A} \beta \mathrm{O}$ increases in the spontaneous firing rate of the mitral cells [9], which in turn send excitatory inputs back to the neurons in the glomerular layer [41]. Supporting our hypothesis that the acute effects in neuronal excitability of the $\mathrm{OB}$ circuits might be involved in the olfactory impairments observed in the present study, Alvarado-Martínez and others [36, 43] have demonstrated alterations in the synchronized activity of the $\mathrm{OB}$ after $\mathrm{A} \beta \mathrm{O}$ exposure, specifically, a decrease in the activation of the granular cell layer, which in turn inhibit the neurons in the mitral cell layer, leading to the hyperexcitability of the MC's and the glomerular layer, ultimately leading to olfactory impairments after $A \beta O$ i.c.v. and intra-bulbar administrations.

In the present study, we report a significant decrease in the amount of NeuN expressing cells in the glomerular layer of the olfactory bulb after $A \beta$ administration, which probably correspond to periglomerular cells and the superficial axon cells [44]. Hence, we hypothesize that this decrease in NeuN might be related to the reported excitotoxic effect of $A \beta[45,46]$, by inducing changes in the excitatory activity or the lateral inhibitory processes 


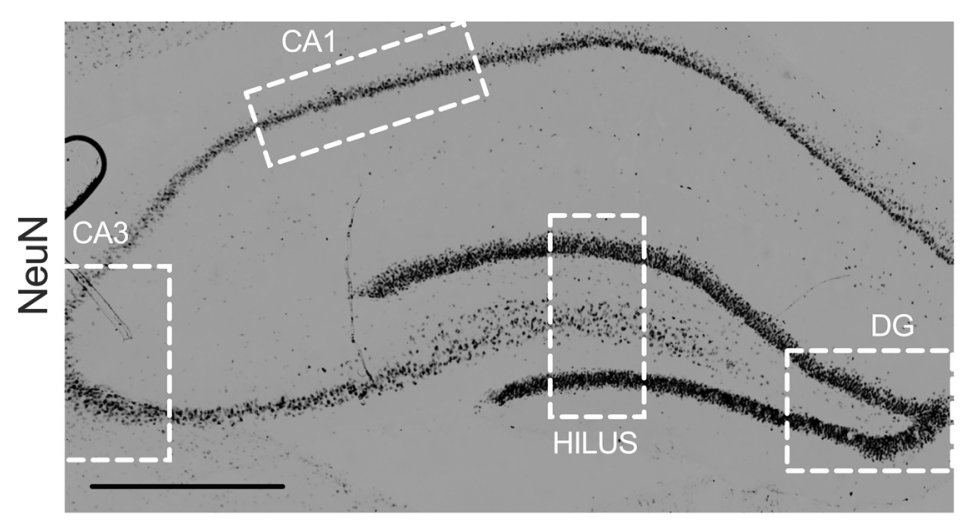

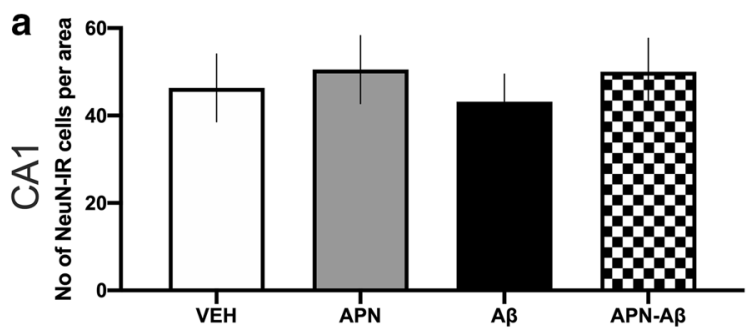
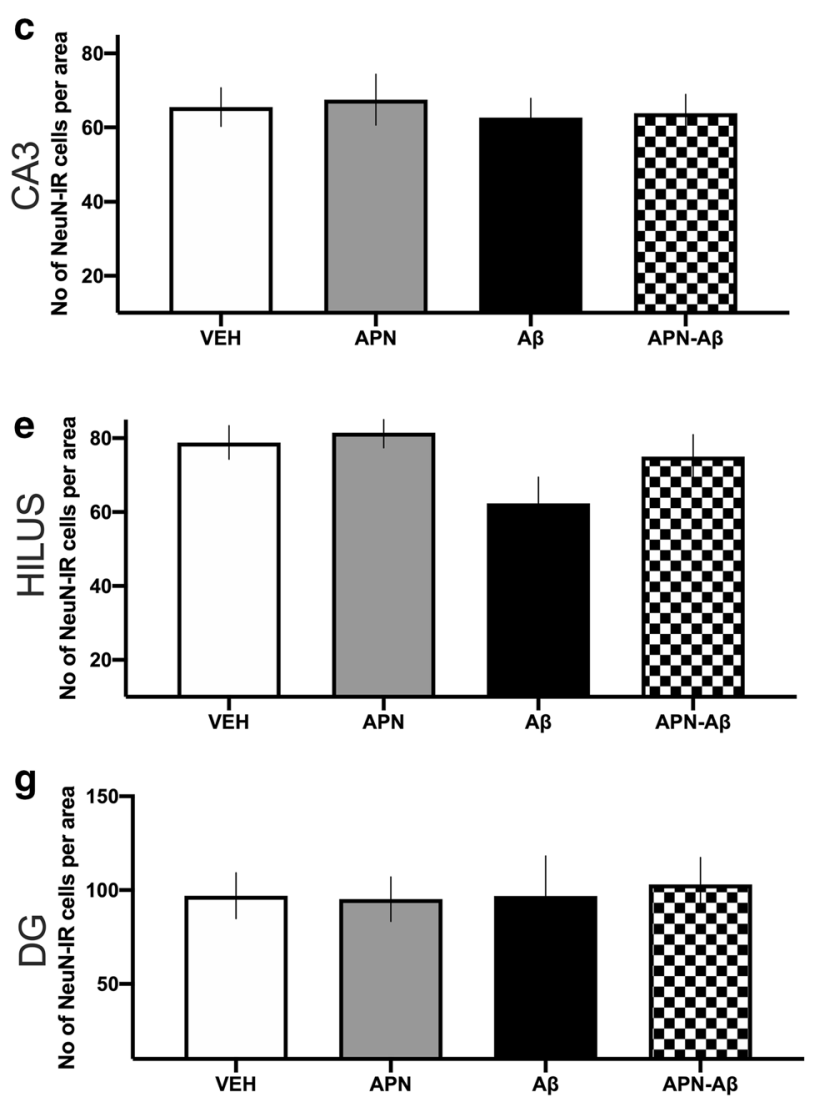

b

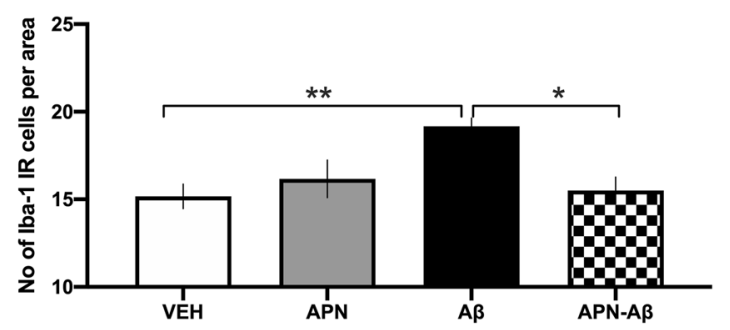

d

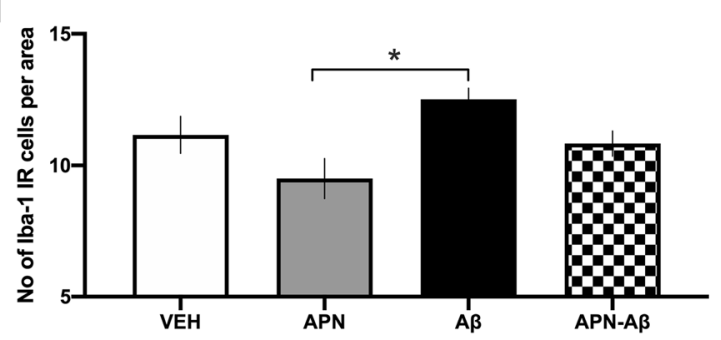

f

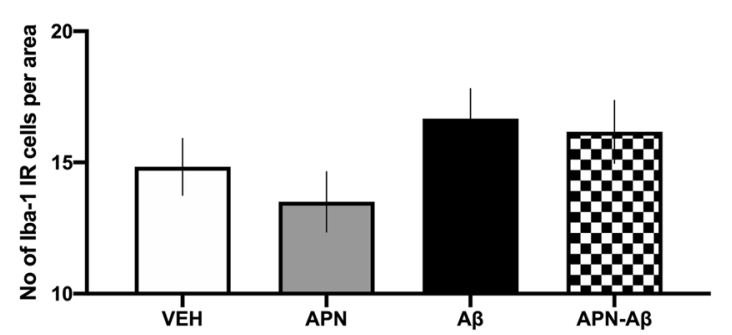

h

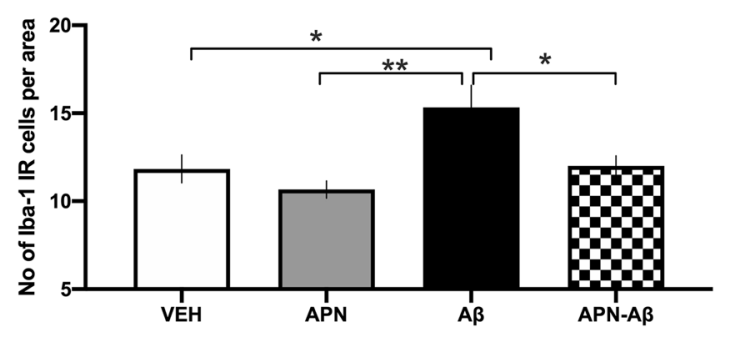




\section{a}

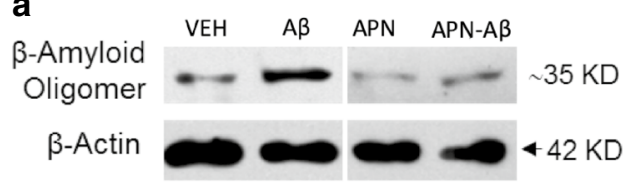

b

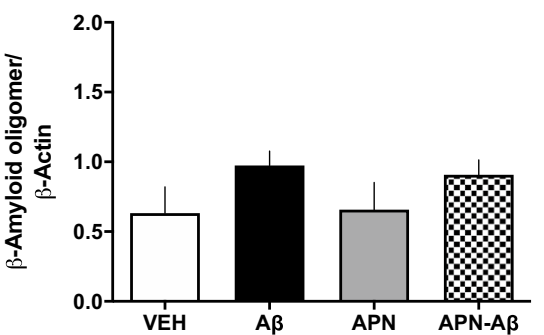

C
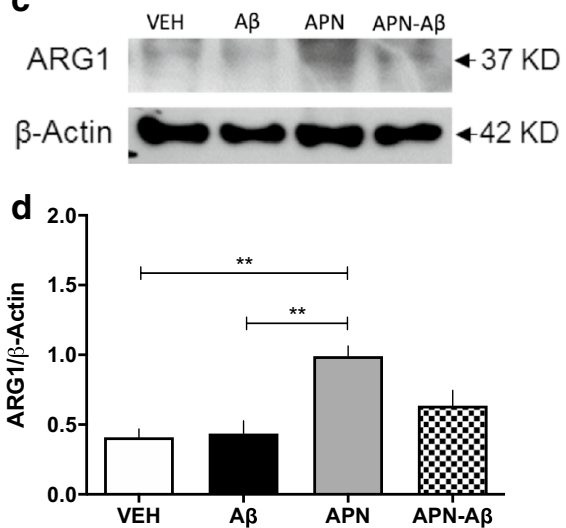

Fig. 5 Protein expression in the hippocampus. a Representative western blot of $\beta$-Amyloid oligomer and $\beta$-Actin; $\mathbf{b} \beta$-Amyloid/ $\beta$-Actin ratio; $\mathbf{c}$ representative western blot of Arginase1 (ARG1) and $\beta$-Actin; $\mathbf{d}$ ARG1/ $\beta$-Actin ratio for the vehicles (VEH), adiponectin (APN), Amyloid- $\beta$ (A $\beta$ ) and APN-A $\beta$ injected rats. Data are presented as SEM and evaluated using a One-way ANOVA with a post-hoc Tukey test

that take place in the GL. Importantly, this layer is one of the first regions affected in the Tg2576 AD genetic model [8], suggesting an increased susceptibility of the GL to the effects of A $\beta O$ 's.

In addition, other authors have demonstrated that i.c.v. administration of $\mathrm{A} \beta \mathrm{O}$ s in mice decreases the number of neurons and the expression of neurotransmitters in the $\mathrm{OB}$, and also increases ROS production resulting in poor olfactory performance [47]. In addition, the i.c.v. delivery of $A \beta$ induces neuronal death mediated by caspase 3 in the rat cortex [48]. Since we did not evaluate cell death or apoptotic markers, the effects observed in NeuN could also be related to a decrease in its expression and not to cell death; future studies should address this possibility.

Although NeuN has been previously used to identify the subpopulations of neurons in the OB [49-52], not all the periglomerular cells express this marker [53]. Therefore, we believe that additional markers like doublecortin, GAD65-67, neurocalcin, tyrosine hydroxylase, among others, should be evaluated in future studies to have a more comprehensive perspective regarding the causes underlying the olfactory impairments observed after the i.c.v. administration of $\mathrm{A} \beta_{1-42}$.

Studies regarding the APN levels in AD patients are controversial, thus the role of this hormone in the pathogenesis of this neurodegenerative disease is not understood [30]. In the present in vivo study, we have shown that APN in the brain prevents the olfactory impairments induced by the administration of i.c.v. $A \beta_{1-42}$. Similar results have been previously reported in a different $A D$ rodent model induced by the i.c.v. administration of streptozotocin (STZ), where i.c.v. APN administration also improved memory [54] suggesting that central APN attenuates STZ induced cognitive impairments.
Furthermore, APN receptors are expressed in the OB [55] and this hormone can enhance the neuronal activation of the neurons in the OB in response to odors [56], which suggests that APN may have a direct effect in olfactory-related regions in the central nervous system.

The protective effects of APN could be due to its neurotrophic and anti-inflammatory role, therefore acting as a neuroprotective agent and thus preventing $\mathrm{A} \beta_{1-42}$ impairments.

APN is known to promote neurogenesis during embryonic development and adulthood due to its neurotrophic properties $[57,58]$. This is in accordance with our data that shows a significant increase in NeuN immunoreactivity in the glomerular layer of the APN-treated rats. In addition, previous reports have demonstrated that APN deficiency reduces the generation of adult granule neurogenesis by suppressing neural progenitor cell proliferation and differentiation [24].

In contrast, i.c.v. APN administration increases neural progenitor cell proliferation in the DG of adult C57BL/6J mice [57]. Furthermore, restoring hippocampal APN levels through exercise in STZ-treated mice (which also present AD like cognitive impairments) restores the number of Ki67 and doublecortin (DCX) positive cells and the ratio of co-labeling of DCX as well as bromodeoxyuridine (BrdU) in the DG [59].

Finally, AdipoR1 activation protects from cell damage and synaptic dysfunction in the brain during hyperglycemia by regulating the survival, proliferation and differentiation of neural stem cells [60]. This proliferative effect of APN is in accordance with our data that shows a significant increase in NeuN immunoreactivity in the glomerular layer of the APN-treated rats and the prevention of the loss of NeuN immunoreactivity in the A $\beta-A P N$ 
group, suggesting that the effects of APN in the OB could be related to this property.

There are no studies determining if APN enhances the proliferation of the neuronal precursors in the subperiventricular zone (SVZ), which is the region responsible for the production of neuroblast precursors that migrating to the $\mathrm{OB}$ to differentiate into interneurons $[61,62]$. Further studies should address whether APN enhances the proliferation of neuroblasts in the SVZ and if these precursors indeed differentiate into neurons in the GL.

One of the limitations of the present study is that we did not evaluate any of the genes/proteins that could indicate if processes such as migration or differentiation were $t$ responsible for the increase in NeuN in both APN and $\mathrm{APN}-\mathrm{A} \beta$ treated rats. Further studies should address the mechanisms involved in the effects of i.c.v. APN in the neurons of the OB.

Olfactory detection tasks are attributed to a circuit in the $\mathrm{OB}$, while odor discrimination, odor formation and storage of olfactory memory also involve an important olfactory-hippocampal pathway [63, 64]. We also evaluated NeuN and Iba-1 expression in the HIPP and observed an increase in the number of Iba- 1 expressing cells in CA1, CA3 and DG of animals treated with $A \beta_{1-42}$ that was prevented by the administration of APN prior to $A \beta_{1-42}$. The number of cells expressing Iba- 1 in the OB did not present changes.

This is one of the few in vivo reports that demonstrate that APN administration in the brain changes Iba-1 expression, which coincides with in vitro data showing that this hormone exerts an important anti-inflammatory effect by preventing microglial neurotoxic activation to phenotype M1; thus decreasing the expression of proinflammatory cytokines like Tumor necrosis factor- $\alpha$ (TNF- $\alpha$ ) and interleukin1- $\beta$ (IL-1 $\beta$ ) in response to the acute exposure to $A \beta O s[26,65,66]$. This suggests that APN in the brain polarizes microglia to the anti-inflammatory M2 phenotype.

In the present paper, we have shown that APN administration increases the amount of ARG-1 in both the OB and the HIPP. This marker is an M2 microglial marker expressed when these cells are activated by anti-inflammatory signals like interleukin-10 (IL-10), transforming growth factor- $\beta$ (TGF- $\beta$ ), IL-13 amongst others [67].

Microglial M2 activation is characterized by the secretion of anti-inflammatory cytokines and increased phagocytosis for debris removal, thus promoting reparation and neuroprotection [55]. APN inhibits the activation of the nuclear factor- $\mathrm{kB}(\mathrm{NF}-\mathrm{\kappa} B$ ) pathway and the cluster of differentiation 68 (CD68), therefore inhibiting the synthesis of IL- $1 \beta$, IL- 6 , and TNF- $\alpha$ in vivo and in vitro, and preventing the cytotoxic actions of microglia $[26,27,66]$. In this sense, APN has clear pleiotropic, including both anti- and pro-inflammatory outcomes.

The effects of APN on the immune response appear to be highly dependent on the isoform and its target tissue [68]. While HMW and MMW isoforms strongly induce chemokine and pro-inflammatory cytokine secretion in rheumatoid arthritis synovial derived fibroblasts, LMW promotes minimal chemokine and cytokine expression [69].

Regarding immune cells, APN administration has shown opposite effects. Studies performed by Wilk et al., show that APN significantly decreases antigenspecific $\mathrm{T}$ cell proliferation and cytokine production [70]. In addition APN-treated dendritic cells have low production of IL-12p40, CD80, CD86, and the major histocompatibility complex class II (MHCII), suggesting a immunomodulatory effect [71]. On the contrary, the administration of APN to polyclonally activated CD4+ T cells enhances proinflammatory cytokine production, thus promoting Th differentiation, which supports its pro-inflammatory role [72].

Furthermore, HMW APN is thought to be responsible for vascular protection through the suppression of TNF- $\alpha$ endothelial secretion [73, 74]. In contrast, globular APN mainly promotes inflammation in cardiomyocytes during acute cardiac disease. Interestingly, this isoform has been reported to inhibit microglial M1 activation via AdipoR1 [75]. In the current study we observed a significant increase in ARG-1 expression, a M2 microglial marker, accompanied with the decrease in the amount of Iba-1 positive cells, suggesting that the effect of our current experimental approach is mainly anti-inflammatory.

Other reports using the same APN brand that we employed show both beneficial and detrimental effects depending on the pathology and the tissue [76-78], suggesting that this recombinant human adiponectin may contain several oligomeric isoforms, and that in the CNS it promotes an anti-inflammatory outcome [75].

Finally, AdipoR1 and AdipoR2 have been reported in both the HIPP an OB [55, 79], thus, we hypothesize that the effects of APN could be mediated through these receptors, since previous studies in our group have demonstrated that i.c.v. APN administration in healthy rats increases the expression of insulin receptors (InsR) [55]. Given that $\mathrm{AD}$ patients tend to present hyperinsulinemia and decreased insulin sensitivity [40, 41], we believe that the beneficial effects of APN in both the OB and the HIPP are mediated by the sensitization of InsR. Future studies should aim to test this hypothesis. 


\section{Conclusion}

In conclusion, we have demonstrated that the olfactory damage caused by the i.c.v. administration of $A \beta$ can be prevented by increasing APN levels in the central nervous system, suggesting that this hormone might prevent the damage associated with $A \beta$ acute administration in our $A \beta_{1-42}$ model. Moreover, we propose further studies aimed to investigate the possible use of APN-based therapies in order to prevent or even ameliorate the progression of $\mathrm{AD}$ and other neurodegenerative diseases.

\section{Methods}

\section{Animals}

This study was conducted in accordance with the guidelines and requirements of the World Medical Association Declaration of Helsinki (1964), approved by the local ethics committee (protocol IN 2015716 Facultad de Medicina, UNAM), and regulated by the Mexican Official Norm NOM-062-ZOO-1999 to minimize animal suffering.

A total of 48 male Wistar rats, 40 adults (248.42 $\mathrm{g} \pm 12.6 \mathrm{~g}$ weight) and 8 juveniles $(112 \pm 6.48 \mathrm{~g}$ weight) from the Faculty of Medicine vivarium, UNAM, were used for the experiments. Animals were maintained under a $12 \mathrm{~h}$ light-dark regime (lights were on from 7 a.m. to 7 p.m.) with water and standard laboratory chow ad libitum (PMI Nutrition International Inc., Greenwood, MO).

\section{Stereotaxic surgery}

All subjects were anesthetized with a ketamine/xylazine mixture $(15 \mathrm{mg} / \mathrm{kg}+1 \mathrm{mg} / \mathrm{kg}$, ip) for i.c.v. stereotaxic surgery, which was performed in a standard rodent stereotaxic frame (David Kopf, USA).

The animals were divided into 4 groups of 8 each: the first group (VEH) was injected with $1 \mu \mathrm{l}$ of isotonic saline solution (SS) followed by $5 \mu \mathrm{l}$ of the same solution $30 \mathrm{~min}$ later; a second group (APN) was injected with $1 \mu \mathrm{l}$ of adiponectin $[150 \mathrm{ng} / \mu \mathrm{l}$ Adiponectin/Acrp (unconjugated) 1065-AP-050, Novus Biologicals] [65] followed by $5 \mu \mathrm{l}$ of SS 30 min later; the third group (A $\beta)$ was first injected with $1 \mu \mathrm{l} \mathrm{SS}$ and 30 min later with $5 \mu \mathrm{l}$ of $\mathrm{A} \beta_{1-42}(1 \mu \mathrm{g} /$ $\mu \mathrm{l}$, Amyloid $\beta$ protein fragment 1-42, Sigma, A9810, dissolved in SS pre-incubated at $37{ }^{\circ} \mathrm{C}$ for $72 \mathrm{~h}$ in a shaking-water bath to induce aggregation); the last group $(\mathrm{APN}-\mathrm{A} \beta$ ) was administered with $1 \mu \mathrm{l}$ of APN and $5 \mu \mathrm{l}$ of $A \beta_{1-42}$. The stereotaxic coordinates employed for i.c.v. injection were measured as $0.92 \mathrm{~mm}$ posterior to bregma; $1.5 \mathrm{~mm}$ lateral to sagittal suture; $3.9 \mathrm{~mm}$ beneath the brain surface [80]. After surgery, animals were housed individually in an acrylic box cage $(50 \times 50 \times 42 \mathrm{~cm})$, and behavioral tests were performed 24,48 and $72 \mathrm{~h}$ after the surgery as previously reported [54]. Animals that did not show alertness and proper motility were discarded from the study.

\section{Experimental design \\ Olfactory tests \\ Social recognition test}

The social recognition test was performed as described previously [81-83]. Briefly, 2 days prior to the experiments and just before the test, adult rats were daily habituated to the testing cage $(50 \times 50 \times 42 \mathrm{~cm})$ for $4 \mathrm{~min}$. Animals were tested $24 \mathrm{~h}$ after the second i.c.v. injection. Only the animals interested in exploring the juveniles were included for posterior analysis (VEH $n=7, A P N$ $\mathrm{n}=6, \mathrm{~A} \beta_{1-42} \mathrm{n}=8, \mathrm{APN}-\mathrm{A} \beta_{1-42}, \mathrm{n}=6$ ).

Each testing session comprised a sequence of three trials of $4 \mathrm{~min}$ each. The time between trials was $10 \mathrm{~min}$, and each trial was recorded for later analysis. During the testing day, the experimental groups were subjected to the three trials: the first one was a habituation period to the testing cage for the adult experimental rats, where we placed two black round metal empty cages (diameter $10 \mathrm{~cm} \times$ tall $16 \mathrm{~cm}$ ) which would serve to enclose the juvenile rats in the following trials. These cages allowed the adult experimental rat to watch and smell, but not touch the juvenile male inside. During the second trial, rats were introduced to the testing cage together with the first unfamiliar juvenile (Training) enclosed in one of the two black metal cages (social memory acquisition); the third trial was a re-exposure to the first juvenile (Familiar) together with a second unfamiliar juvenile (Novel), both simultaneously presented inside the two black metal cages; this third trial was performed $60 \mathrm{~min}$ after the social memory acquisition. Following each test, the cage was thoroughly cleaned with $70 \%$ ethanol. Video recording of investigatory behavior was used to assess the time spent by adult rats investigating the stimulus animal in the social recognition test. We quantified the time that the animals spent investigating the unfamiliar and the familiar juveniles and the time the animals explored the black metal cages during the habituation period.

\section{Habituation-dishabituation test}

Habituation-dishabituation behavior is also used for the assessment of olfactory memory by observing the 'rewarded olfactory discrimination' ability of subjects. Animals were tested $24 \mathrm{~h}$ after the i.c.v. injection. The habituation/dishabituation test was performed using histological cartridges holding cotton swab scented with different extracts, corresponding to complex odors that have been previously reported for this test [81, 83, 84]. We only included the animals that were interested in 
exploring the water cartridges at the beginning of the test $(\mathrm{VEH} n=8, \mathrm{APN} n=5, \mathrm{~A} \beta \mathrm{n}=7, \mathrm{APN}-\mathrm{A} \beta \mathrm{n}=5)$.

Habituation was done in a different testing room from the one where we prepared the scented cottons. We placed a small cotton ball into a clean cartridge with $50 \mu \mathrm{l}$ of coconut extract (DEIMAN) and placed it inside the testing cage for $30 \mathrm{~s} 3$ consecutive times with a $10 \mathrm{~min}$ intervals between each placement. Later, we performed the same procedure for a second scent, banana extract (DEIMAN). The manipulation of the cartridges was done with different gloves for each scent.

Every trial was recorded and blindly evaluated, we quantified the time rats spent sniffing the cartridges in each trial, determining sniffing as the moment the animals pointed the nose towards the cartridges and a clear movement of the whiskers was observed. We also considered picking up the cartridges with the paws as sniffing behavior.

\section{Block test}

This second social recognition test was performed $48 \mathrm{~h}$ after the surgeries, the subjects were exposed to blocks from their own cage and from a non-self cage. Exploration time for each block was quantified, following previously reported procedures for mice [84-86] with minor modifications to make the test suitable for rats. Only the animals interested in exploring the cubes were included $(\mathrm{VEH} n=7, \mathrm{APN} n=6, \mathrm{~A} \beta \mathrm{n}=6, \mathrm{APN}-\mathrm{A} \beta \mathrm{n}=8$ ).

Briefly, 4 plastic blocks (labeled A-D, 1 -inch $\times 1$-inch $\times 1$-inch) were placed inside the clean home cages of individually housed rats $24 \mathrm{~h}$ before the test. $1 \mathrm{~h}$ prior to testing, the blocks were removed and placed inside Ziploc bags on top of the housing cages for one hour. In the first six trials, we placed each animals' own $\mathrm{A}, \mathrm{B}$ and $\mathrm{C}$ blocks, then, we removed the blocks from the cage and placed them back into the bag; this was done 6 times with intervals of 5 min between each trial. On the 7th trial, we followed the same procedure, except that instead of placing block $C$ from the rat's own cage, we replaced it with block $\mathrm{D}$ from another rat's cage. We determined the time the animals explored the alien block, as compared to that of blocks A-B. The manipulation of the blocks was done with different gloves for each rat.

\section{Animal euthanasia}

$72 \mathrm{~h}$ after the i.c.v. injections, rats were anaesthetized with an overdose of sodium pentobarbital (Sedalphorte, $65 \mathrm{mg} / \mathrm{ml}$ ) and perfused with $50 \mathrm{ml}$ of $0.9 \%$ saline followed by $250 \mathrm{ml}$ of fixative $4 \%$ paraformaldehyde in phosphate buffer saline (PBS, $0.1 \mathrm{M}, \mathrm{pH}$ 7.2). The time between anesthesia and fixation was 5 min. Brains were removed and post-fixed for $24 \mathrm{~h}$ in paraformaldehyde
$4 \%$. After post fixation, brains were cryoprotected in $30 \%$ sucrose for 3-4 days for further immunohistochemistry analysis.

\section{Histological assessments Immunohistochemistry}

Brains were frozen and cut at $-18{ }^{\circ} \mathrm{C}$. Serial sections $(40 \mu \mathrm{m})$ were coronally cut with a cryostat (LEICA, CM1850) and collected in PBS $0.1 \mathrm{M}$ with $0.1 \%$ sodium azide.

In order to stain mature neurons, a primary antibody against NeuN (monoclonal mouse anti-NeuN, Abcam Cat \#ab104224; 1:500) and a biotinylated secondary antibody (anti-mouse, made in horse Vector; 1:500) were used. The $\mathrm{ABC}$ and peroxidase substrate kits (Vector) were used to visualize bound antibody and the sections were further stained with diaminobenzidine.

To stain microglial cells, a primary antibody against Iba-1 (monoclonal goat anti-Iba-1, Abcam Cat \#ab5076; 1:1000) and a biotinylated secondary antibody (anti-goat, made in donkey Jackson; 1:500) were used. The $A B C$ and peroxidase substrate kit (Elite, Vector) was used to visualize bound antibody and the sections were further stained with diaminobenzidine.

The neurons in the granular cell layer (GCL) and the glomerular layer (GL) in the $\mathrm{OB}$, and $\mathrm{CA} 1, \mathrm{CA} 3$, hilus and DG in the HIPP were identified and evaluated using a NIKON microscope (eclipse 50i). The images were digitalized with a DS-U2 S Camera at 5 and $20 \times$ (PlanApochromat $^{\circledR}, 1.25 \mathrm{NA} / 160$ ).

The latter quantifications were performed on gray-scale images with a $20 \times$ objective lens and computer-assisted imaging analysis system (Image J) software (National Institutes of Health, USA).

\section{Immunohistological analysis}

We evaluated the number of cells per area in 3 different rectangular selections inside the granular and glomerular layers of the OB and the CA1, 3, hilus and DG in the HIPP, respectively. The placement of the 3 rectangles inside each region of interest was randomly assigned by creating 4 different personalized Macros in ImageJ/FIJI (see Fig. 2 for the OB regions and S2 for the HIPP regions which include examples of the rectangle placements). These Macros allowed us to automatize the quantification areas, instead of manually placing them in order to ensure an unbiased quantification of the number of cells in each one of the regions. We quantified 4 sections of each region including left and right of six rats per group and the average per rat was reported, this evaluation was performed by 2 evaluators blind to the treatments. 


\section{Western blot}

Protein extraction of 4 rats per group was performed using NP-40 lysis buffer containing protease inhibitors (Complete, Roche). $30 \mu \mathrm{g}$ of protein per condition was run on $10 \%$ SDS-PAGE gels and then transferred to nitrocellulose membranes (BioRad) which were subsequently blocked for $1 \mathrm{~h}$ with a solution of 3\% BSA in TBS $/ 0.05 \%$ Tween or $5 \%$ skim milk in TBS/0.05\% Tween (for $\beta$-Amyloid). Membranes were incubated overnight with primary antibodies against Arginase 1 (1:8000, PA518684 Invitrogen), $\beta$-Amyloid (1:1000, sc-53822 Santa Cruz Biotechnology) and $\beta$-Actin (1:5000, GTX629630 GeneTex). Subsequent rinsing was performed with TBS/0.05\% Tween and then membranes were incubated for $1 \mathrm{~h}$ with anti-goat or anti-mouse secondary antibodies diluted 1:10,000 (Santa Cruz Biotechnology), followed by a second rinsing with TBS/0.05\% Tween. The presence of proteins was revealed by chemiluminescence (WBLUF0500, Millipore). The images were captured using MiniBIS Pro imaging system (DNR Systems Imaging-Bio Ltd.). Densitometry analysis was performed using Image J 1.52a software.

\section{Statistical analysis}

Social recognition test was evaluated with a Students T test, habituation-dishabituation, the block tests and WB were evaluated by performing a One-way ANOVA with a post-hoc Tukey test. NeuN and Iba-1 data were evaluated with a One-way ANOVA with a post-hoc Tukey test. Comparisons between Intact and vehicle treated animals were done using a series of unpaired Student's T tests. Results were considered to be statistically significant if $\mathrm{p} \leq 0.05$. Graphs and statistical analyses were elaborated using the GraphPad Prism version 8 for macOS, GraphPad Software, La Jolla, California, USA.

\footnotetext{
Abbreviations

AD: Alzheimer's disease; AdipoR: Adiponectin receptor; $A \beta$ : Amyloid beta; $A \beta O$ : $A \beta$ oligomers; $A \beta_{1-42}$ : Amyloid-beta ${ }_{1-42} ; A \beta P P / P S 1$ : Familial mouse model of AD; APN: Adiponectin; APN-A $\beta_{1-42}$ : Adiponectin-amyloid-beta ${ }_{1-42}$ APN-KO: APN knockout; APPsw: APP transgenic mouse, also known as Tg2576; ARG-1: Arginase-1; BV2: Microglial cell line; BrdU: Bromodeoxyuridine; CD68: Cluster of differentiation 68; CSF: Cerebrospinal fluid; DG: Dentate gyrus; DCX: Doublecortin; Fig.: Figure; GCL: Granule cell layer; HIPP: Hippocampus; HT-22: Hippocampal neuronal cell line; i.c.v.: Intracerebroventricular; Iba-1: Ionized calcium-binding adapter molecule 1; IL-1 $\beta$ : Interleukin 1- $\beta$; IL-10: Interleukin-10; InsR: Insulin receptor; IRS-1: Receptor substrate-1; LMW: Low molecular weight; M1: Microglial neurotoxic activation; M2: Microglial anti-inflammatory activation; MCs: Mitral cells; MHCll: Major histocompatibility complex class II; MMW: Middle molecular weight; NeuN: Neuronal nuclei; NF-kB: Nuclear factor-kB; OB: Olfactory bulb; PC: Periglomerular cells; p-TAU: Phosphorylated microtubule-associated protein tau; sSA: Superficial axon cells; SS: Saline solution; STZ: Streptozotocin; SVZ: Sub-periventricular zone; TGF- $\beta$ : Transforming growth factor- $\beta$; TNF-a: Tumor necrosis factor-a; VEH: Vehicle.
}

\section{Supplementary Information}

The online version contains supplementary material available at https://doi. org/10.1186/s12868-021-00620-9.

Additional file 1: Figure S1. Olfactory tests in intact and vehicletreated animals. (A) Social recognition test for intact and vehicle (VEH) treated rats, unpaired Student's T test for Novel-1 intact vs. VEH:T $=1.43$, $d f=15, p=0.2962$, Familiar intact vs. VEH: $T=1.702, d f=15, p=0.6413$ and Novel-2 intact vs. VEH: $T=1.396, d f=15, p=0.9322$. (B) Block test, unpaired Student's T test for block A intact vs. VEH: $T=1.405, \mathrm{df}=15$, $\mathrm{p}=0.18$, block $B$ vs. VEH: $T=0.1823, \mathrm{df}=15, \mathrm{p}=0.8578$ and block $\mathrm{C}$ intact vs. VEH: $T=0.7088, d f=15, p=0.4893$. (C) Habituation-dishabituation test (Two-way ANOVA interaction: $F_{[8,54]}=0.58, p=0.7849$, Sidak's multiple comparisons post hoc test did not show significant differences). Data are presented as SEM.

Additional file 2: Figure S2. NeuN and IBA-1 representative micrographs for CA1, CA3, hilus and the dentated gyrus of the hippocampus. CA1 (scale bar for NEUN $100 \mu \mathrm{m}$ IBA-1 $150 \mu \mathrm{m}$ ), CA3 (scale bar for $50 \mu \mathrm{m}$ ), hilus (scale bar for NeuN $100 \mu \mathrm{m}$ and for IBA-1 $80 \mu \mathrm{m}$ ), DG (scale bar for NEUN $50 \mu \mathrm{m}$ and for IBA-1 $100 \mu \mathrm{m})$

Additional file 3: Figure S3. Full-length blots of $A \beta$ oligomer detection in the olfactory bulb and hippocampus. (A) A $B$ oligomer blots of the experimental groups Veh (vehicle), $A \beta_{1-42}$, APN (adiponectin) and $A P N+A \beta_{1-42}$. (B) $A \beta$ oligomer blots of the experimental groups with increased exposition. ( $C$ and $D$ ) Corresponding $\beta$-Actin blots of the experimental groups. Densitometryc analysis was performed using $A$ and $D$ images for olfactory bulb and $B$ and $C$ images for hippocampus samples.

Additional file 4: Figure S4. Full-lenght blots of ARG1 and GFAP detection in the olfactory bulb and hippocampus. (A) ARG1 and GFAP blots of the experimental groups Veh (vehicle), $A \beta_{1-42}$, APN (adiponectin) and $A P N+A \beta_{1-42}$. ARG1 (37KD) and GFAP (50 KD) were run in the same blots. (B) Corrsponding $\beta$-Actin blots of the experimental groups. HP: hippocampus, BO: olfactory bulb.

\section{Acknowledgements}

Doctor Mara Alaide Guzmán-Ruiz is part of the Subprograma de Incorporación de Jóvenes Académicos de Carrera (SIJA), UNAM. The authors like to thank doctors Virginia Selene Arriaga Ávila, Carlos Bernal-Mondragón, Natalí N Guerrero-Vargas, Diana Cruz-Acosta and Jorge Márquez for their technical support. Authors would also like to thank María Josefina Bolado Garza, Head of the Translation Department of the Research Division, Facultad de Medicina, UNAM and Rebeca Méndez-Hernández for proof-reading.

\section{Authors' contributions}

MAGR performed experiments, designed the olfactory tests, performed the stereotaxic surgeries, processed biological samples, acquired Iba-1 microphotograpies, analyzed the data and wrote the manuscript; AHG performed the olfactory evaluations; AJ and CCD performed WB's and helped in the preparation of the manuscript; ACJ and CQL performed the stereotaxic surgeries and processed brain tissue for IHC; EOS performed NeuN IHC and acquired the microphotograpies; DOJ performed statistical analyses and helped in the preparation of the manuscript; SDC donated NeuN antibody and contributed in designing the olfactory tests; and, RGG designed the study, provided financial support and wrote the manuscript. All authors read and approved the final manuscript.

\section{Funding}

This study was supported by grant DGAPA-PAPIIT IN-IN215716 to RGG. Doctor Adriana Jiménez is part of the Programa de Becas Posdoctorales de la Dirección General de Asuntos del Personal Académico (DGAPA), División de Investigación, Facultad de Medicina, Universidad Nacional Autónoma de México (UNAM). The funding bodies played no role in the design of the study and collection, analysis, and interpretation of data and in writing the manuscript.

Availability of data and materials

All data generated or analyzed during this study are included in this published article. 


\section{Declarations}

\section{Ethics approval and consent to participate}

Experimental procedures used in this study were in strict accordance with the Mexican norm for animal handling, Norma Oficial Mexicana NOM-062ZOO-1999, which conforms to international guidelines for ethics and animal handling aimed to minimize the number of animals used and their suffering. The experiments were approved by the Ethics Committee (063/2016) in the Faculty of Medicine, UNAM.

\section{Consent for publication}

Not applicable.

\section{Competing interests}

The authors declare that they have no competing interests.

\section{Author details}

1 Departamento de Fisiología, Facultad de Medicina, Universidad Nacional Autónoma de México (UNAM), Mexico City, Mexico. ${ }^{2}$ Departamento de Neurobiología del desarrollo y neurofisiología, Instituto de Neurobiología, Universidad Nacional Autónoma de México (UNAM), Querétaro, Mexico.

Received: 20 February 2020 Accepted: 23 February 2021

Published online: 02 March 2021

\section{References}

1. Serrano-Pozo A, Frosch MP, Masliah E, Hyman BT. Neuropathological alterations in Alzheimer disease. Cold Spring Harb Perspect Med. 2011;1:a006189.

2. Polanco JC, Li C, Bodea L-G, Martinez-Marmol R, Meunier FA, Götz J. Amyloid- $\beta$ and tau complexity - towards improved biomarkers and targeted therapies. Nat Rev Neurol. 2018;14:22-39.

3. El Haj M. Memory suppression in Alzheimer's disease. Neurol Sci. 2016;37:337-43

4. Wesson DW, Wilson DA, Nixon RA. Should olfactory dysfunction be used as a biomarker of Alzheimer's disease? Expert Rev Neurother. 2010:10:633-5.

5. de Silva M, Mercer PBS, Witt MCZ, Pessoa RR. Olfactory dysfunction in Alzheimer's disease systematic review and meta-analysis. Dement Neuropsychol. 2018;12:123-32.

6. Wu N, Rao X, Gao Y, Wang J, Xu F. Amyloid- $\beta$ deposition and olfactory dysfunction in an Alzheimer's disease model. J Alzheimer's Dis. 2013:37:699-712.

7. Marin C, Vilas D, Langdon C, Alobid I, López-Chacón M, Haehner A, et al. Olfactory dysfunction in neurodegenerative diseases. Curr Allergy Asthma Rep. 2018. https://doi.org/10.1007/s11882-018-0796-4.

8. Wesson DW, Levy E, Nixon RA, Wilson DA. Olfactory dysfunction correlates with amyloid-burden in an Alzheimer's disease mouse model. J Neurosci. 2010;30:505-14

9. Hu B, Geng C, Hou X-Y. Oligomeric amyloid- $\beta$ peptide disrupts olfactory information output by impairment of local inhibitory circuits in rat olfactory bulb. Neurobiol Aging. 2017;51:113-21.

10. Xu W, Fitzgerald S, Nixon RA, Levy E, Wilson DA. Early hyperactivity in lateral entorhinal cortex is associated with elevated levels of ABPP metabolites in the Tg2576 mouse model of Alzheimer's disease. Exp Neurol. 2015;264:82-91

11. Pugazhenthi S, Qin L, Reddy PH. Common neurodegenerative pathways in obesity, diabetes, and Alzheimer's disease. Biochim Biophys Acta (BBA) Mol Basis Dis. 2017:1863:1037-45.

12. Raffaitin C, Gin H, Empana J-P, Helmer C, Berr C, Tzourio C, et al. Metabolic syndrome and risk for incident Alzheimer's disease or vascular dementia: the three-city study. Diabetes Care. 2009;32:169-74.

13. Wang ZV, Scherer PE. Adiponectin, the past two decades. J Mol Cell Biol. 2016:8:93-100

14. Escobar-Morreale HF. Adiponectin and resistin in PCOS: a clinical, biochemical and molecular genetic study. Hum Reprod. 2006;21:2257-65.
15. Aroda V, Ciaraldi TP, Chang S-A, Dahan MH, Chang RJ, Henry RR. Circulating and cellular adiponectin in polycystic ovary syndrome: relationship to glucose tolerance and insulin action. Fertil Steril. 2008;89:1200-8.

16. Glintborg D, Frystyk J, Højlund K, Andersen KK, Henriksen JE, Hermann AP, et al. Total and high molecular weight (HMW) adiponectin levels and measures of glucose and lipid metabolism following pioglitazone treatment in a randomized placebo-controlled study in polycystic ovary syndrome. Clin Endocrinol. 2007;68(2):165-74.

17. Ding M, Rzucidlo EM, Davey JC, Xie Y, Liu R, Jin Y, et al. Adiponectin in the heart and vascular system. Vitam Horm. 2012;90:289-319.

18. Ruan H, Dong LQ. Adiponectin signaling and function in insulin target tissues. J Mol Cell Biol. 2016:8:101-9.

19. Teixeira AL, Diniz BS, Campos AC, Miranda AS, Rocha NP, Talib LL, et al. Decreased levels of circulating adiponectin in mild cognitive impairment and Alzheimer's disease. Neuromol Med. 2013;15:115-21.

20. Ali T, Yoon GH, Shah SA, Lee HY, Kim MO. Osmotin attenuates amyloid beta-induced memory impairment, tau phosphorylation and neurodegeneration in the mouse hippocampus. Sci Rep. 2015. https://doi.org/10. 1038/srep11708.

21. Yamauchi T, Kamon J, Waki H, Terauchi Y, Kubota N, Hara K, et al. The fatderived hormone adiponectin reverses insulin resistance associated with both lipoatrophy and obesity. Nat Med. 2001;7:941-6.

22. Hug C, Wang J, Ahmad NS, Bogan JS, Tsao T-S, Lodish HF. T-cadherin is a receptor for hexameric and high-molecular-weight forms of Acrp30/ adiponectin. Proc Natl Acad Sci. 2004;101:10308-13.

23. Ranscht B, Dours-Zimmermann MT. T-cadherin, a novel cadherin cell adhesion molecule in the nervous system lacks the conserved cytoplasmic region. Neuron. 1991;7:391-402.

24. Ng RCL, Cheng OY, Jian M, Kwan JSC, Ho PWL, Cheng KKY, et al. Chronic adiponectin deficiency leads to Alzheimer's disease-like cognitive impairments and pathologies through AMPK inactivation and cerebral insulin resistance in aged mice. Mol Neurodegener. 2016. https://doi.org/10. 1186/s13024-016-0136-x

25. Kadowaki T. Adiponectin and adiponectin receptors in insulin resistance, diabetes, and the metabolic syndrome. J Clin Investig. 2006;1 16:1784-92.

26. Jian M, Kwan JSC, Bunting M, Ng RCL, Chan KH. Adiponectin suppresses amyloid- $\beta$ oligomer (A $\beta O)$-induced inflammatory response of microglia via AdipoR1-AMPK-NF-KB signaling pathway. J Neuroinflamm. 2019. https://doi.org/10.1186/s12974-019-1492-6.

27. Nicolas S, Cazareth J, Zarif H, Guyon A, Heurteaux C, Chabry J, et al. Globular adiponectin limits microglia pro-inflammatory phenotype through an AdipoR1/NF-kB signaling pathway. Front Cell Neurosci. 2017. https://doi. org/10.3389/fncel.2017.00352.

28. Chen B, Liao W-Q, Xu N, Xu H, Wen J-Y, Yu C-A, et al. Adiponectin protects against cerebral ischemia-reperfusion injury through anti-inflammatory action. Brain Res. 2009:1273:129-37.

29. Kim MW, Bin Abid N, Jo MH, Jo MG, Yoon GH, Kim MO. Suppression of adiponectin receptor 1 promotes memory dysfunction and Alzheimer's disease-like pathologies. Sci Rep. 2017. https://doi.org/10.1038/ s41598-017-12632-9.

30. Une K, Takei YA, Tomita N, Asamura T, Ohrui T, Furukawa K, et al. Adiponectin in plasma and cerebrospinal fluid in $\mathrm{MCl}$ and Alzheimer's disease: adiponectin in dementia. Eur J Neurol. 2011:18:1006-9.

31. Waragai M, Adame A, Trinh I, Sekiyama K, Takamatsu Y, Une K, et al. Possible involvement of adiponectin, the anti-diabetes molecule, in the pathogenesis of Alzheimer's disease. J Alzheimer's Dis. 2016;52:1453-9.

32. Fukumoto $H$, Tokuda $T$, Kasai T, Ishigami $N$, Hidaka $H$, Kondo M, et al. Highmolecular-weight $\beta$-amyloid oligomers are elevated in cerebrospinal fluid of Alzheimer patients. FASEB J. 2010;24:2716-26.

33. Ruiz-Muñoz AM, Nieto-Escamez FA, Aznar S, Colomina MT, SanchezSanted F. Cognitive and histological disturbances after chlorpyrifos exposure and chronic $A \beta(1-42)$ infusions in Wistar rats. Neurotoxicology. 2011;32:836-44.

34. Choi JY, Yeo IJ, Kim KC, Choi WR, Jung J-K, Han S-B, et al. K284-6111 prevents the amyloid beta-induced neuroinflammation and impairment of recognition memory through inhibition of NF-kB-mediated CHI3L1 expression. J Neuroinflamm. 2018. https://doi.org/10.1186/ s12974-018-1269-3.

35. Yamada K, Tanaka T, Mamiya T, Shiotani T, Kameyama T, Nabeshima T. Improvement by nefiracetam of $\beta$-amyloid-(1-42)-induced learning and memory impairments in rats. Br J Pharmacol. 1999:126:235-44. 
36. Hernández-Soto R, Rojas-García KD, Peña-Ortega F. Sudden intrabulbar amyloid increase simultaneously disrupts olfactory bulb oscillations and odor detection. Neural Plast. 2019;2019:1-11.

37. Bateman RJ, Munsell LY, Morris JC, Swarm R, Yarasheski KE, Holtzman DM. Human amyloid- $\beta$ synthesis and clearance rates as measured in cerebrospinal fluid in vivo. Nat Med. 2006;12:856-61.

38. Cetin F, Yazihan N, Dincer S, Akbulut G. The effect of intracerebroventricular injection of beta amyloid peptide (1-42) on caspase-3 activity, lipid peroxidation, nitric oxide and nos expression in young adult and aged rat brain. Turk Neurosurg. 2012. https://doi.org/10.5137/1019-5149.JTN. 5855-12.1.

39. Zhang L, Fang Y, Xu Y, Lian Y, Xie N, Wu T, et al. Curcumin improves amyloid $\beta$-peptide (1-42) induced spatial memory deficits through BDNF-ERK signaling pathway. PLoS ONE. 2015;10:e0131525.

40. Wang Y, Liu J, Zhang Z, Bi P, Qi Z, Zhang C. Anti-neuroinflammation effect of ginsenoside $\mathrm{Rbl}$ in a rat model of Alzheimer disease. Neurosci Lett. 2011;487:70-2.

41. Nagayama S, Homma R, Imamura F. Neuronal organization of olfactory bulb circuits. Front Neural Circuits. 2014. https://doi.org/10.3389/fncir. 2014.00098.

42. Cao L, Schrank BR, Rodriguez S, Benz EG, Moulia TW, Rickenbacher GT, et al. $A \beta$ alters the connectivity of olfactory neurons in the absence of amyloid plaques in vivo. Nat Commun. 2012. https://doi.org/10.1038/ncomm s2013.

43. Alvarado-Martínez R, Salgado-Puga K, Peña-Ortega F. Amyloid beta inhibits olfactory bulb activity and the ability to smell. PLOS ONE. 2013;8:e75745

44. Parrish-Aungst S, Shipley MT, Erdelyi F, Szabo G, Puche AC. Quantitative analysis of neuronal diversity in the mouse olfactory bulb. J Comp Neurol. 2007;501:825-36.

45. Pallo SP, DiMaio J, Cook A, Nilsson B, Johnson GVW. Mechanisms of tau and $A \beta$-induced excitotoxicity. Brain Res. 2016;1634:119-31.

46. Esposito Z, Belli L, Toniolo S, Sancesario G, Bianconi C, Martorana A. Amyloid $\beta$, glutamate, excitotoxicity in Alzheimer's disease: are we on the right track? CNS Neurosci Ther. 2013;19:549-55.

47. Raj A, Dey S, Maheshwari DU, Manjula SN, Madhunapantula SV, Ali M. Evaluating the olfactory dysfunction and cognitive deficits induced by intracerebroventricular injection of Amyloid beta (1-42) in female C57BL/6 mice. J Appl Pharm Sci. 2019;9:24-34.

48. Giridharan W, Thandavarayan RA, Arumugam S, Mizuno M, Nawa H, Suzuki K, et al. Schisandrin B ameliorates ICV-infused amyloid $\beta$ induced oxidative stress and neuronal dysfunction through inhibiting RAGE/ NF-KB/MAPK and up-regulating HSP/Beclin expression. PLOS ONE. 2015;10:e0142483.

49. Hwang IK, Lee JC, Cho JH, Yoo K-Y, Kim DS, Nam YS, et al. Very delayed neuronal loss occurs in the glomerular layer of the main olfactory bulb following transient ischemia in gerbils. Neurosci Lett. 2004;366:272-6.

50. Zou J, Pan Y-W, Wang Z, Chang S-Y, Wang W, Wang X, et al. Targeted deletion of ERK5 MAP kinase in the developing nervous system impairs development of gabaergic interneurons in the main olfactory bulb and behavioral discrimination between structurally similar odorants. J Neurosci. 2012;32:4118-32.

51. Richard MB, Taylor SR, Greer CA. Age-induced disruption of selective olfactory bulb synaptic circuits. Proc Natl Acad Sci. 2010;107:15613-8.

52. Taguchi K, Watanabe Y, Tsujimura A, Tanaka M. a-Synuclein promotes maturation of immature juxtaglomerular neurons in the mouse olfactory bulb. Mol Neurobiol. 2020:57:1291-304.

53. Bagley J, LaRocca G, Jimenez DA, Urban NN. Adult neurogenesis and specific replacement of interneuron subtypes in the mouse main olfactory bulb. BMC Neurosci. 2007:8:92.

54. Mazrooie R, Rohampour K, Zamani M, Hosseinmardi N, Zeraati M. Intracerebroventricular administration of adiponectin attenuates streptozotocin-induced memory impairment in rats. Physiol Int. 2017;104:150-7.

55. Miranda-Martínez A, Mercado-Gómez OF, Arriaga-Ávila V, GuevaraGuzmán R. Distribution of adiponectin receptors 1 and 2 in the rat olfactory bulb and the effect of adiponectin injection on insulin receptor expression. Int J Endocrinol. 2017;2017:1-9.

56. Loch D, Heidel C, Breer H, Strotmann J. Adiponectin enhances the responsiveness of the olfactory system. PLoS ONE. 2013;8:e75716.
57. Zhang D, Wang X, Lu X-Y. Adiponectin exerts neurotrophic effects on dendritic arborization, spinogenesis, and neurogenesis of the dentate gyrus of male mice. Endocrinology. 2016;157:2853-69.

58. Zhang D, Wang X, Wang B, Garza JC, Fang X, Wang J, et al. Adiponectin regulates contextual fear extinction and intrinsic excitability of dentate gyrus granule neurons through AdipoR2 receptors. Mol Psychiatry. 2017;22:1044-55.

59. Yau SY, Lee THY, Li A, Xu A, So KF. Adiponectin mediates running-restored hippocampal neurogenesis in streptozotocin-induced type 1 diabetes in mice. Front Neurosci. 2018. https://doi.org/10.3389/fnins.2018.00679.

60. Song J, Kang SM, Kim E, Kim C-H, Song H-T, Lee JE. Adiponectin receptormediated signaling ameliorates cerebral cell damage and regulates the neurogenesis of neural stem cells at high glucose concentrations: an in vivo and in vitro study. Cell Death Dis. 2015;6:e1844-e1844.

61. Lim DA, Alvarez-Buylla A. The adult ventricular-subventricular zone (V-SVZ) and olfactory bulb (OB) neurogenesis. Cold Spring Harb Perspect Biol. 2016;8:a018820.

62. Mastroeni D, Chouliaras L, Van den Hove DL, Nolz J, Rutten BPF, Delvaux E, et al. Increased 5-hydroxymethylation levels in the sub ventricular zone of the Alzheimer's brain. Neuroepigenetics. 2016;6:26-31.

63. Vanderwolf $\mathrm{CH}$. The hippocampus as an olfacto-motor mechanism: were the classical anatomists right after all? Behav Brain Res. 2001;127:25-47.

64. Aboitiz F, Montiel JF. Olfaction, navigation, and the origin of isocortex. Front Neurosci. 2015. https://doi.org/10.3389/fnins.2015.00402.

65. Ouchi N, Walsh K. Adiponectin as an anti-inflammatory factor. Clin Chim Acta. 2007;380:24-30.

66. Song J, Choi S-M, Kim BC. Adiponectin regulates the polarization and function of microglia via PPAR- $\gamma$ signaling under amyloid $\beta$ toxicity. Front Cell Neurosci. 2017. https://doi.org/10.3389/fncel.2017.00064.

67. Yao K, Zu H. Microglial polarization: novel therapeutic mechanism against Alzheimer's disease. Inflammopharmacology. 2020:28:95-110.

68. Hutcheson J. Adipokines influence the inflammatory balance in autoimmunity. Cytokine. 2015;75:272-9.

69. Frommer KW, Schäffler A, Büchler C, Steinmeyer J, Rickert M, Rehart S, et al. Adiponectin isoforms: a potential therapeutic target in rheumatoid arthritis? Ann Rheum Dis. 2012;71:1724-32.

70. Wilk S, Scheibenbogen C, Bauer S, Jenke A, Rother M, Guerreiro M, et al. Adiponectin is a negative regulator of antigen-activated T cells. Eur J Immunol. 2011;41:2323-32.

71. Tsang JYS, Li D, Ho D, Peng J, Xu A, Lamb J, et al. Novel immunomodulatory effects of adiponectin on dendritic cell functions. Int Immunopharmacol. 2011;11:604-9.

72. Cheng X, Folco EJ, Shimizu K, Libby P. Adiponectin induces pro-inflammatory programs in human macrophages and CD4+ T cells. J Biol Chem. 2012;287:36896-904

73. Kobayashi H, Ouchi N, Kihara S, Walsh K, Kumada M, Abe Y, et al. Selective suppression of endothelial cell apoptosis by the high molecular weight form of adiponectin. Circ Res. 2004. https://doi.org/10.1161/01.RES.00001 19921.86460 .37$.

74. Tomizawa A, Hattori Y, Kasai K, Nakano Y. Adiponectin induces NF-KB activation that leads to suppression of cytokine-induced NF-KB activation in vascular endothelial cells: globular adiponectin vs. high molecular weight adiponectin. Diabetes Vasc Dis Res. 2008:5:123-7.

75. Nicolas S, Cazareth J, Zarif H, Guyon A, Heurteaux C, Chabry J, et al. Globular adiponectin limits microglia pro-inflammatory phenotype through an AdipoR1/NF-kB signaling pathway. Front Cell Neurosci. 2017;11:352.

76. Chen HT, Tsou HK, Chen JC, Shih JMK, Chen YJ, Tang CH. Adiponectin enhances intercellular adhesion molecule-1 expression and promotes monocyte adhesion in human synovial fibroblasts. PLOS ONE. 2014:9:e92741.

77. Lavoie V, Kernaleguen A-E, Charron G, Farhat N, Cossette M, Mamarbachi AM, et al. Functional effects of adiponectin on endothelial progenitor cells. Obesity. 2011;19:722-8.

78. Fu S, Xu H, Gu M, Liu C, Wang Q, Wan X, et al. Adiponectin deficiency contributes to the development and progression of benign prostatic hyperplasia in obesity. Sci Rep. 2017;7:43771.

79. Repunte-Canonigo V, Berton F, Cottone P, Reifel-Miller A, Roberts AJ, Morales M, et al. A potential role for adiponectin receptor 2 (AdipoR2) in the regulation of alcohol intake. Brain Res. 2010;1339:11-7. 
80. Yamaguchi Y, Kawashima S. Effects of amyloid- $\beta$-(25-35) on passive avoidance, radial-arm maze learning and choline acetyltransferase activity in the rat. Eur J Pharmacol. 2001;412:265-72.

81. Guevara-Guzmán R, Arriaga V, Kendrick KM, Bernal C, Vega X, MercadoGómez OF, et al. Estradiol prevents ozone-induced increases in brain lipid peroxidation and impaired social recognition memory in female rats. Neuroscience. 2009;159:940-50.

82. Rivas-Arancibia S, Guevara-Guzmán R, López-Vidal Y, Rodríguez-Martínez E, Zanardo-Gomes M, Angoa-Pérez M, et al. Oxidative stress caused by ozone exposure induces loss of brain repair in the hippocampus of adult rats. Toxicol Sci. 2010;113:187-97.

83. Jiménez A, Organista-Juárez D, Torres-Castro A, Guzmán-Ruíz MA, Estudillo E, Guevara-Guzmán R. Olfactory dysfunction in diabetic rats is associated with miR-146a overexpression and inflammation. Neurochem Res. 2020;45:1781-90
84. Lehmkuhl AM, Dirr ER, Fleming SM. Olfactory assays for mouse models of neurodegenerative disease. J Vis Exp. 2014. https://doi.org/10.3791/ 51804.

85. Tillerson JL, Caudle WM, Parent JM, Gong C, Schallert T, Miller GW. Olfactory discrimination deficits in mice lacking the dopamine transporter or the D2 dopamine receptor. Behav Brain Res. 2006;172:97-105.

86. Taylor TN, Caudle WM, Miller GW. VMAT2-deficient mice display nigral and extranigral pathology and motor and nonmotor symptoms of Parkinson's disease. Parkinson's Dis. 2011;2011:1-9.

\section{Publisher's Note}

Springer Nature remains neutral with regard to jurisdictional claims in published maps and institutional affiliations.
Ready to submit your research? Choose BMC and benefit from:

- fast, convenient online submission

- thorough peer review by experienced researchers in your field

- rapid publication on acceptance

- support for research data, including large and complex data types

- gold Open Access which fosters wider collaboration and increased citations

- maximum visibility for your research: over $100 \mathrm{M}$ website views per year

At BMC, research is always in progress.

Learn more biomedcentral.com/submissions 